\title{
The study of the effect of fault transmissibility on the reservoir production using reservoir simulation-Cornea Field, Western Australia
}

\author{
Nurafiqah Abdullah ${ }^{1} \cdot$ Nurul Hasan $^{1}\left[\right.$ D $\cdot$ Nawaf Saeid $^{2} \cdot$ Mysara Eissa Mohyaldinn ${ }^{3}$. \\ El-Said Mamdouh Mahmoud Zahran ${ }^{4}$
}

Received: 5 August 2019 / Accepted: 2 October 2019 / Published online: 1 November 2019

(c) The Author(s) 2019

\begin{abstract}
The focused area in this study is in the Cornea Field located in the Yampi Shelf, north-eastern Browse Basin, Australia. The field was stated to be an elongated unfaulted drape anticline over highly eroded basement. From the literature and seismic data, faults die at the basement in the Cornea Field. Therefore, no faults were considered previously. The tectonic activity was not apparent in the area with only deformation by gravitational movements and compaction in the basement zone. However, fault might present in the reservoir and seal depth as time passed. Therefore, the aim of this study is to simulate the Cornea field with faults, to determine the effect of fault transmissibility on oil production. The study shows that the fault permeability and fault displacement thickness ratio have a close relationship with fault transmissibility. The fault transmissibility increases when fault permeability and fault displacement thickness ratio increase. Transmissibility multiplier was also considered in this study. The fault transmissibility increases with the increase in transmissibility multiplier, thus the oil production. This study contributes to the gap present in the research of the Cornea Field with fault structure, where it is important to consider fault existence during exploration and production.
\end{abstract}

Keywords Unfaulted drape $\cdot$ Fault permeability $\cdot$ Fault displacement thickness ratio $\cdot$ Transmissibility multiplier $\cdot$ Oil production

$\begin{array}{ll}\text { Abbreviations } \\ \text { MBBL } & \text { Million barrels } \\ \text { BFPD } & \text { Barrel of fluid per day } \\ \text { MMCFPD } & \text { Million cubic feet per day } \\ \text { HRDZ } & \begin{array}{l}\text { Hydrogen-related diagenetic zone } \\ \text { SAIGUP }\end{array} \\ & \begin{array}{l}\text { Sensitivity analysis of the impact of geologi- } \\ \text { cal uncertainties on production }\end{array} \\ \text { STOOIP } & \begin{array}{l}\text { Stock tank oil in place (stb) } \\ \text { TM }\end{array} \\ \text { Transmissibility multiplier }\end{array}$

Nurul Hasan

nurulhasan@asme.org

1 PCE, Universiti Teknologi Brunei, Gadong BE 1410, Brunei Darussalam

2 Mechanical Engineering, Universiti Teknologi Brunei, Gadong BE 1410, Brunei Darussalam

3 Petroleum Engineering, Universiti Teknologi PETRONAS, Ipoh, Perak, Malaysia

4 Civil Engineering, Universiti Teknologi Brunei, Bandar Seri Begawan 1410, Brunei Darussalam

\begin{tabular}{ll}
\multicolumn{2}{l}{ Subscripts and superscripts } \\
Trans $_{i j}$ & Transmissibility in $i$ and $j$ grid blocks \\
$L_{i} L_{i}$ & Distance in $i$ and $j$ directions \\
$K_{i} K_{i}$ & Permeability in $i$ and $j$ blocks \\
TransF $_{i j}$ & Fault transmissibility in $i$ and $j$ grid blocks \\
$K_{\mathrm{f}}$ & Fault permeability in $i$ and $j$ blocks \\
$t_{\mathrm{f}}$ & Fault thickness \\
$Z_{\mathrm{f}}$ & Depth at time of deformation \\
$Z_{\mathrm{max}}$ & Maximum rock burial depth \\
$V_{\mathrm{f}}$ & Fault rock clay content \\
$D$ & Fault displacement (m) \\
$\mathrm{SGR}$ & Frictional shale gauge ratio \\
$A$ & Area (acre) \\
$h$ & Reservoir thickness (ft) \\
$\varnothing$ & Rock porosity (\%) \\
$S_{\mathrm{wc}}$ & Connate water saturation (\%) \\
$B_{\mathrm{oi}}$ & Oil formation volume factor (rb/stb)
\end{tabular}




\section{Introduction}

The Cornea Field is located offshore Western Australia, in the Yampi Shelf of the north-eastern Browse Basin with an area of approximately $1755 \mathrm{~km}^{2}$. The Browse Basin was an extensional half-graben, with upper crustal faulting resulted in half-graben geometry with large-scale normal fault compartmentalizing the basin into sub-basin. Extensional faulting was concentrated on the north-eastern part of Caswell Sub-Basin and western margin of Prudhoe Terrace, and this formed Heywood Graben (Australia and Australia Geoscience 2011a, b; Australia 2012a; Michele 1999; Tuohy 2009a; Poidevin et al. 2015). The Yampi Shelf is located at the transition zone between two major compartments. The boundary zone was acted as the fault relay zone (Fig. 1). However, the fault displacement on the Yampi Shelf depleted to the northeast area (Obriena et al. 2005) stated that the fault and trap reactivation was minimal to absent across the Yampi Shelf and considered not an important feature. However, seal integrity was more likely to occur. Gas chimneys and hydrogen-related diagenetic zones (HRDZs) spread over the accretion and extended to the regional seal on laps the basement highs on the east. Alkaif (2015) also showed that from the literature and seismic data (Ishak et al. 2018) faults die at the basement in the Cornea Field. Ingram et al. (2000) also stated that the tectonic activity was not apparent in the area with only deformation by gravitational movements and compaction in the basement zone. Therefore, no faults were considered.

The Cornea structure is a simple trap configuration consisting of a large, elongated, four-way dip closure formed by an unfaulted drape anticline of the Albian sandstone (comprised of zones A, B, C, D and E) of upper Heywood Formation over an eroded basement high (Fig. 2). The hydrocarbon accumulation consists of an expanded gas cap over a thin discontinuous oil rim (Poidevin et al. 2015). Most studies showed that the fault was unlikely to be present in the

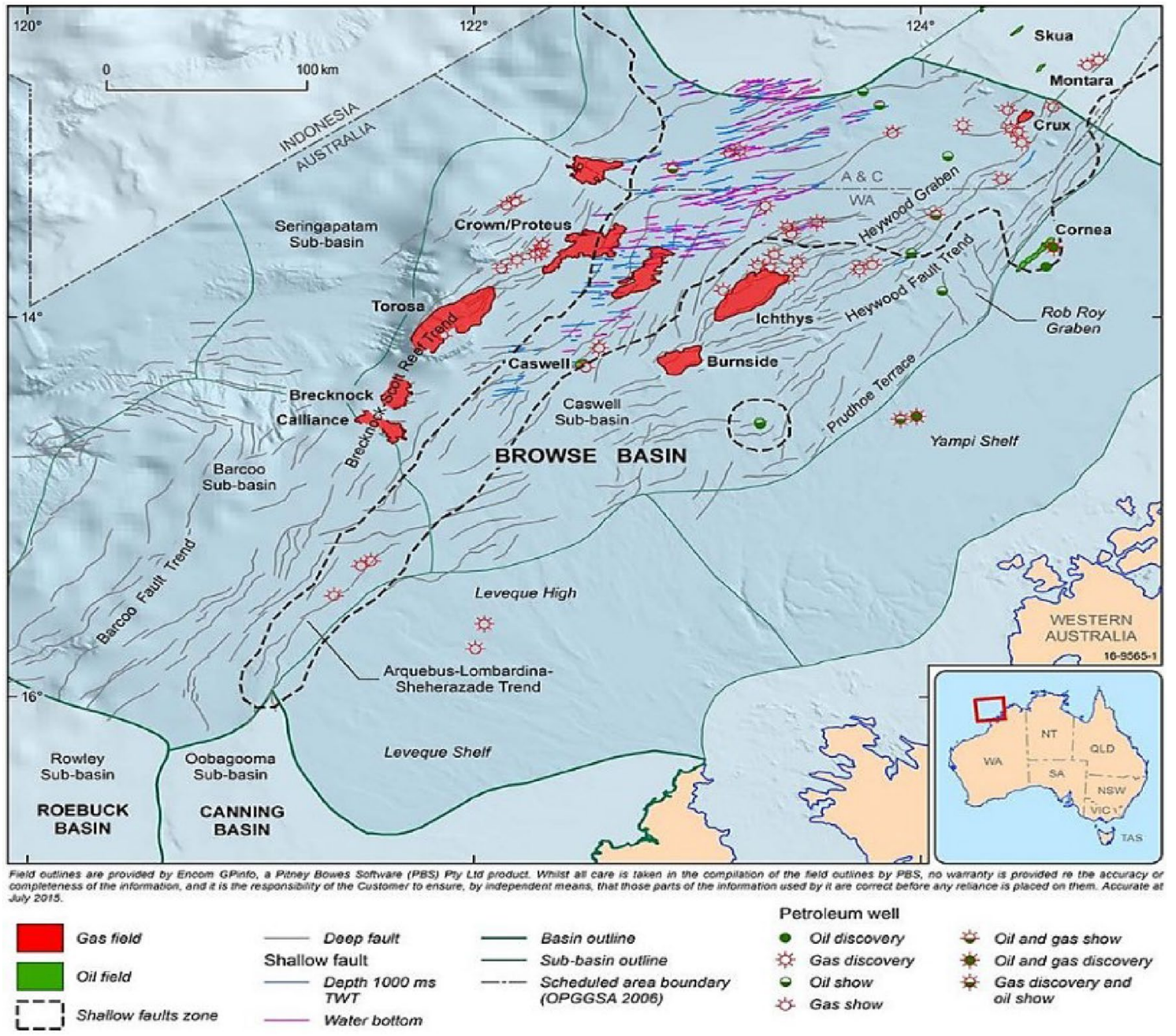

Fig. 1 Structural element of Browse Basin: Cornea Field on the upper right side of the map (black lines represent faults) (Australia 2012b) 
Cornea Field. However, there were faults existed around the Yampi Shelf zone where Cornea Field is located so there is a possibility for faults to developed in the reservoir. Ingram et al. (2000) stated that fault may not be present in the seismic; however, fault might present in the reservoir and seal depth. Sea floor was seen to demonstrate some linear features in the seismic, and there is a possibility of a strike-slip fault due to near surface stress disturbance. A significant amount of hydrocarbon has been discovered in the cornea field, and also a commercial development of the Cornea Oil Field is possible.

However, there were challenges involved in the evaluation (Naser et al. 2007) of the productivity of the wells and the recovery of the oil production (Ltd 2014). Therefore, the aim of this study is to consider the fault existence in the Cornea field and to foresee the effect of the fault transmissibility on the Cornea Field that might impact the reservoir production. There are three areas in the Cornea Field: Cornea South, Cornea Central and Cornea North. This paper only focuses on Cornea South and Cornea Central.

Research done in 1999 by Michele G. Bishop stated that the Cornea 1 was reported to have encountered from 600 MBBL $\left(95 \times 10^{6} \mathrm{sm}^{3}\right)$ of oil to $2.6 \mathrm{BBBL}\left(413 \times 10^{6} \mathrm{sm}^{3}\right)$ of oil in place. This discovery was considered to be the first commercially producible oil in the Browse Basin. The
Cornea discovery proved that a large volume of oil has been generated in the mature central portion of the basin; however, no production tests were attempted and it was confirmed that migration and charge have occurred (Australia and Australia Geoscience 2011b; Australia 2012b; Bishop 1999).

In 2010, exploration activities on the Cornea Field were completed by Cornea Resources Pty Ltd. Cornea Resources Pty Ltd indicated that Cornea Field was one of the undeveloped potential oil fields in Australia. A large number of exploration and appraisal wells were being drilled into the accumulation. A significant amount of hydrocarbon was discovered from the samples obtained, where the quantum of contingent resources in Cornea was reasonably expected to be economic as long as production flow rates can be achieved. Cornea Field was estimated to have a P50 of 411 $\operatorname{MBBL}\left(65 \times 10^{6} \mathrm{~m}^{3}\right)$. However, productivity of the reservoir has not been proved (Ltd 2014).

Appraisal project was also done by Octanex in order to invest on the Cornea oil field, which had the potential of future feasible development upon the appraisal. The Cornea 1 well resulted in a discovery of a gas cap which showed in the seismic and oil leg within upper Heywood formation. A drill stem test (DST) was conducted at this well with 14.4 BFPD and 0.3 MMCFPD gas (Khan et al. 2006) obtained. However, even

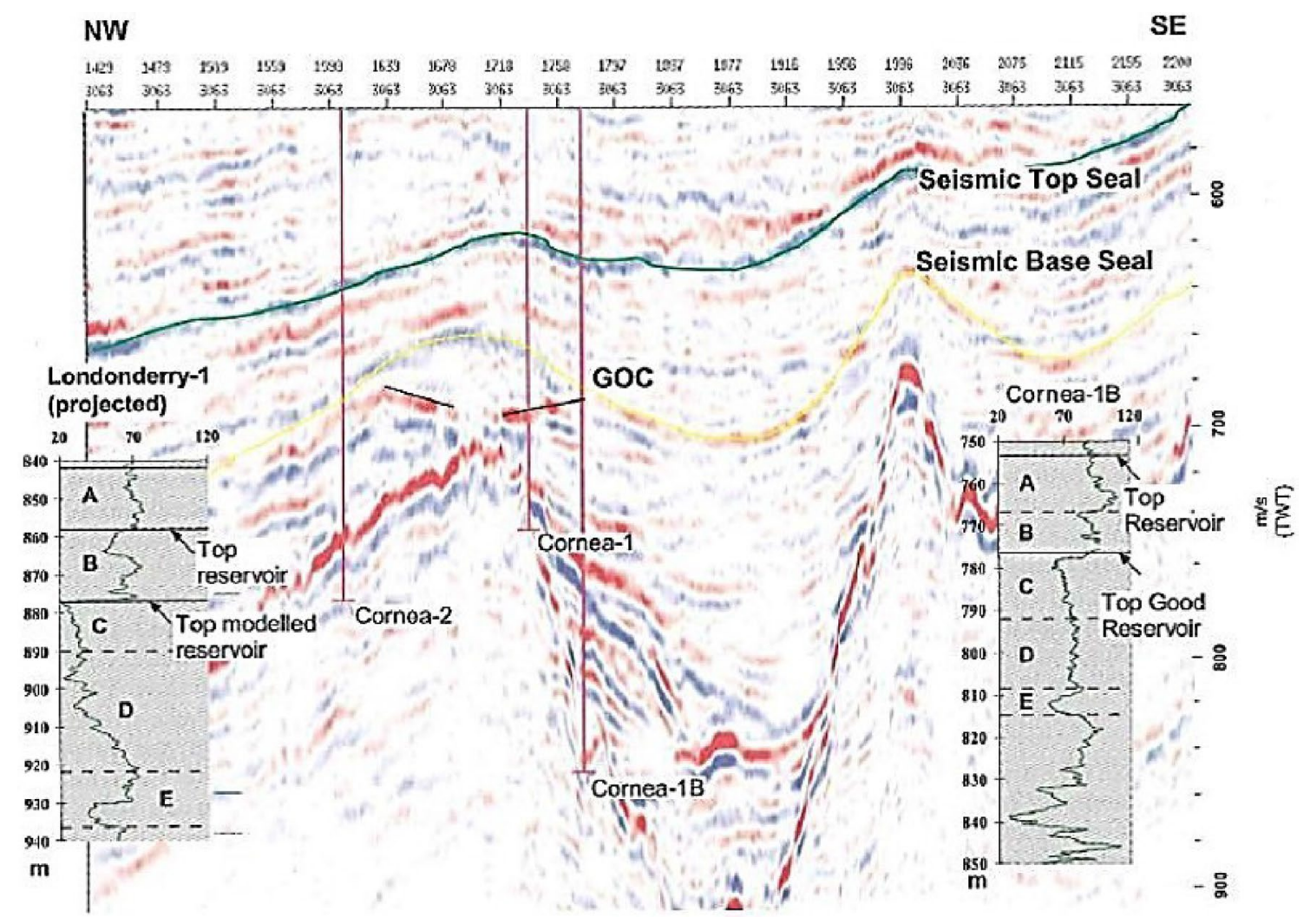

Fig. 2 Seismic lines across Cornea Field (Ingram et al. 2000)

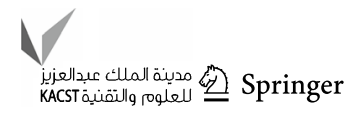




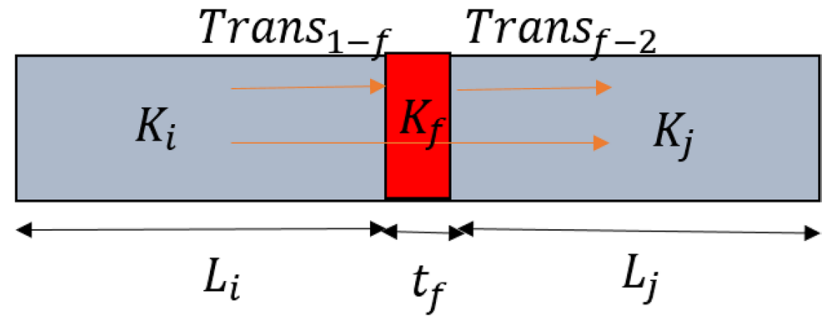

Fig. 3 Illustration of fault transmissibility in a pair of grid blocks with fault permeability and thickness

with the amount of the oil and gas encountered, the appraisal project did not come up to their expectation on the Cornea Field. Therefore, by reprocessing the Cornea seismic, Shell indicated that a great amount of oil resources may exist within sands B, C and E that could be further developed by using multilateral horizontal wells (Tuohy 2009a; Limited 2010).

On the other hand, RPS Energy Pty Ltd reviewed the Cornea Field seismic, well data and other data and estimated the in-place volumes and recoverable volumes of the field. They stated that with only one DST flow conducted by Shell from Cornea South 2ST1, there were insufficient data to conclude that Cornea well production would match the production levels in real life. However, the volume between Top B gross reservoir map and the Base $\mathrm{C}$ gross reservoir was calculated. The calculated oil in place was P50 159 MBBL $\left(25 \times 10^{6} \mathrm{sm}^{3}\right)$. RPS also estimated that the recovery factor at lowest was $15 \%$, best at 25\% and highest at 35\% (Tuohy 2009b).

The presence of fault can impact the production of the reservoir. Costa et al. (2016) stated that the fault within the petroleum reservoir acted as a barrier or flow for fluid. Therefore, it was important to know the fault properties in order to optimize (Khan et al. 2012) the recovery factor. This had dramatically helped the industry to predict the impact of fault on fluid flow and also decreased the risk of exploration in the faulted zone. Fault transmissibility is one of the factors that need to be considered in oil recovery. Fault transmissibility in a reservoir simulation model depends on the grid block geometry as shown in Zhalehrajabi et al. (2014) and Rashid et al. (2014a); permeability and transmissibility multiplier are applied to the faces of the grid blocks (Fig. 3). To determine the fault transmissibility multiplier, fault properties such as fault thickness and fault permeability are required.

Manzocchi et al. (2008) studied the performance of the faulted and unfaulted in the shallow marine reservoir model. There were nine different cases tested in the reservoir model. The result showed that the oil production rate was highly correlated with the fault permeability case, while the recovery factor was highest in the intermediate fault case. However, when the fault becomes less permeable, the production and the recovery factor decreased rapidly (Manzocchi et al. 2008; Houwers et al. 2015; Flodin and Durlofsky 2001;
Kimura et al. 2015; Wenning et al. 2018), while Rotevatn and Fossen (2011) focused on evaluation of the subseismic fault element on the hydrocarbon exploration and production. The production and pressure data set obtained was simulated. The focused area was in the Colorado Plateau of South East Utah. Rotevatn and Fossen (2011) stated that the dimension of the fault system was important to be understood for better exploration. The low permeable fault resulted in aquifer support in the reservoir and thus enhanced production. From the flow simulation, it proves that lowering the fault permeability led to increase in sweep efficiency and recovery by increasing the injection fluid flow (Rashid et al. 2014b) and set back water breakthrough (Rotevatn and Fossen 2011; Fisher and Jolley 2007; Paul et al. 2007). This had an opposite result with Manzocchi et al. (2008) since there was aquifer support in this reservoir and water was injected into the reservoir to boost the recovery.

Byberg (2009) aimed to investigate the effect of dynamic behavior of the reservoir by applying transmissibility multiplier to the fault to achieve history match and to determine its effect on field production. History-matched A-Lunde reservoir simulation model was used as reference for the study. After running simulation, it showed that there was an increased in oil production of $1.4 \mathrm{M} \mathrm{SM}^{3}$ with fault model. It also showed that the higher the value of the fault transmissibility multiplier, the higher the oil production. Thus, by varying the fault transmissibility, there was a significant impact on the field performance.

Toft et al. (2012) estimated the potential recovery of the segment H1 in Gullfaks. The segment H1 was injected with a chemical called Abio Gel due to oil residual stayed in the low permeable zone. Six Eclipse simulation scenarios were done by applying different transmissibility multipliers to reservoir volume. The result of the simulation showed a significant increase in total oil production with increasing transmissibility multipliers.

In addition, Frischbutter et al. (2017) conducted a fault analysis from core and seismic scale (Sern et al. 2012) to assess the effect of the faults on the production and recoverable volumes in the Upper Jurassic reservoir, Norwegian offshore sector. The reservoir consisted of many compartmentalizations by depositional fault. The fault permeability was examined at high confining pressures using formation compatible brines. It was used to calculate the transmissibility multiplier that was integrated into the reservoir model to measure the impact of fault on fluid flow. The dynamic reservoir simulations showed that more than $20 \%$ recoverable volumes depending on the fault properties inserted in the simulation. Therefore, it was proved that the fault existence can impact the cumulative recoverable oil volumes and the recovery efficient (Frischbutter et al. 2017; Manzocchi et al. 1999; Ahmed 2013). The fault architecture indicates the fault shape, size, orientation and connectivity are important to be considered. Therefore, the importance of the fault properties in 
the reservoir structure needs to be taken into consideration, especially during hydrocarbon drilling, exploration and production stage (A TNO-CSIRO-ISES Joint Industry Project 2009; Taylor 2016; Manzocchi et al. 2010; Zijlstra et al. 2016; Cerveny et al. 2005; Sorkhabi and Tsuji 2005; Wennberg et al. 2012).

In conclusion, many studies have been conducted on the fault related to the reservoir production. Despite that, the uniqueness of this study is to simulate the fault into the Cornea Field, which initially did not have fault structure that exists in the reservoir. The objectives of this study are:

- To focus on the Cornea South and Cornea Central Field (data available for this part only)

- To develop dynamic model of Cornea Field

- To simulate fault structures in the Cornea Field reservoir

- To evaluate the fault permeability and fault displacement thickness ratio effects on transmissibility

- To test the transmissibility multiplier effects on the transmissibility and oil production.

\section{Methodology}

Data were collected from different available sources. In constructing the 3D model, the following data were needed:

Data collection (Australia and Australia Geoscience 1998a, b; Geoscience Australia 1997)

Data source

\section{Well Data}

Well Headers Geoscience Australia-Well Completion Report

Well Deviation Geoscience Australia-Well Completion Report

Well Log Occam Technology Company (Mr Mike Wiltshire)

2. Well Tops Geoscience Australia-Well Completion Report

\section{3D Seismic Data}

Reservoir Boundary polygon estimation

4. Fault Data Fault polygon estimation

The 3D model was constructed in PETREL using the data extracted from the literature review, Geoscience Australia and Occam Technology Company (Australia and Australia Geoscience 1998a, b; Geoscience Australia 1997). It was proved that fault did not exist in the Cornea Field and also no fault data are available. Therefore, the fault characteristic and displacement were assumed, in order to fit the objective of this paper. As mentioned from the literature review, extensional faulting exists within the area of the Cornea Field. Therefore, normal fault was considered in this case. The location of the fault was randomly picked. Two faults were assumed and constructed in the Cornea Field. In order to construct the fault, fault polygons were generated in the mapping application. The fault polygons data were imported to the model (Khan et al. 2003) and generated by fault modeling process. Pillar gridding has a close relationship with the fault model. The concept of the pillar gridding is to construct the skeleton framework for top, mid- and base skeleton that connects the top, mid- and base key pillars to generate 3D grid. The last step was to insert the horizons by inputting the surfaces, zones generation and layering to construct the fine-scale layering 3D model (Zene et al. 2019; Witt et al. 2007).

The unfaulted model was calibrated by modifying the porosity (Saeid et al. 2018) using ECLIPSE keyword MULTIPLY to match with the literature-reviewed oil in place in the reservoir to have a more realistic model. The fault was constructed after model (Khan et al. 2001) calibration. See Table 5 for original oil in place data. Sensitivity analysis was done by varying fault permeability and fault displacement-to-thickness ratio to test the uncertainty in transmissibility. Transmissibility multiplier MULTFLT keyword in ECLIPSE was used to test its effects on the fault transmissibility and oil production. There were two algorithms considered: Monzhocchi and Sperrevik algorithm, in calculating the fault permeability, Eqs. (1) and (2). The fault displacement-to-thickness ratio formula is shown in Eqs. (3) and (4).

$\log k_{\mathrm{f}}=-4 \mathrm{SGR}-\frac{1}{4} \mathrm{LOG}(D)(1-\mathrm{SGR})^{5}$

$k_{\mathrm{f}}=a_{1} \exp$

$$
\left(-\left(a_{2} V_{\mathrm{f}}+a_{3} z_{\max }+\left(a_{4} z_{\mathrm{f}}-a_{5}\right)\left(1-V_{\mathrm{f}}\right)^{7}\right]\right\}
$$

where

$a_{1}=80000$

$a_{2}=19.4$

$a_{3}=0.00403$

$a_{4}=0.0055$

$a_{5}=12.5$

Hull, 1988

$t_{\mathrm{f}}=\frac{D}{66}$

Walsh, 1998

$t_{\mathrm{f}}=\frac{D}{170}$

To capture effectively the fault transmissibility (Fig. 4), fault transmissibility multiplier needs to be calculated.

$\operatorname{Trans}_{i j}=\left(\frac{2}{\frac{L_{i}}{K_{i}}+\frac{L_{j}}{K_{j}}}\right)$ 


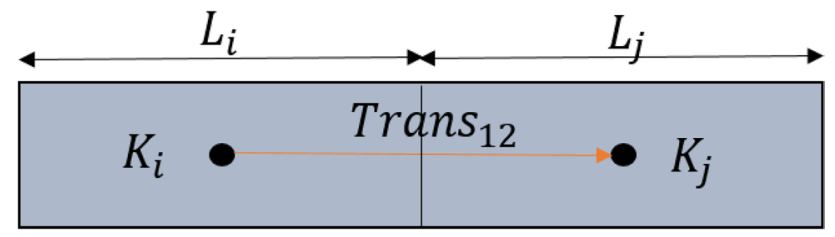

Fig. 4 Illustration of transmissibility in a pair of grid blocks

$\operatorname{TransF}_{i j}=\left(\frac{2}{\frac{L_{i}-t_{\mathrm{f}}}{K_{i}}+\frac{2 t_{\mathrm{f}}}{K_{\mathrm{f}}}+\frac{L_{j}-t_{\mathrm{f}}}{K_{j}}}\right)$

Transmissibility multiplier, $\mathrm{TM}=\frac{\operatorname{TransF}_{i j}}{\text { Trans }_{i j}}$

$$
=\frac{\left(\frac{2}{\frac{L_{i}-\digamma_{f}}{K_{i}}+\frac{2 L_{f}}{K_{\mathrm{f}}}+\frac{L_{j}-T_{\mathrm{f}}}{K_{j}}}\right)}{\left.\left(\frac{2}{\frac{L_{i}}{K_{i}}}\right) \frac{L_{j}}{K_{j}}\right)}
$$

The volumetric recoverable oil production (STOOIP) was calculated (Table 1) from volume calculation in Petrel as shown in Eq. (8). The stock tank oil in place calculation is:

$\mathrm{STOOIP}=\frac{7758 A h \varnothing\left(1-S_{\mathrm{wc}}\right)}{B_{\mathrm{oi}}}$

The detail of the computer hardware is attached in "Appendix."

\section{Results}

Figure 5 shows the porosity map of the unfaulted model of the Cornea Field with dimension of $134 \mathrm{~m} \times 160 \mathrm{~m} \times 50 \mathrm{~m}$. The well production is Cornea 1, Cornea 1B, Cornea South 1 and Cornea South 2 ST1. The illustrated model shows Unit $\mathrm{B}$, Unit C, oil water contact, producible oil water contact layers. The active unit in the Cornea Field is Unit B and Unit C. Porosities are higher in the Cornea South 1 and Cornea South 2ST1 well region. This indicates that there is more hydrocarbon accumulation in this region. Table 2 shows the initial condition and fluid condition extracted from well completion report. Table 3 states the porosity data for Cornea 1, Cornea 1B, Cornea South 1 and Cornea South 2ST1 wells. Table 4 shows the permeability data for Cornea 1 , Cornea 1B, Cornea South 1 and Cornea South 2ST1 wells.
Table 1 Original oil in place data

\begin{tabular}{lll}
\hline Model & Porosity & OOIP \\
\hline Unfaulted & 0.19 & $65 \times 10^{6} \mathrm{~m}^{3}$ \\
Faulted & 0.19 & $52 \times 10^{6} \mathrm{~m}^{3}$ \\
\hline
\end{tabular}

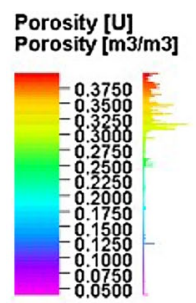

(7)

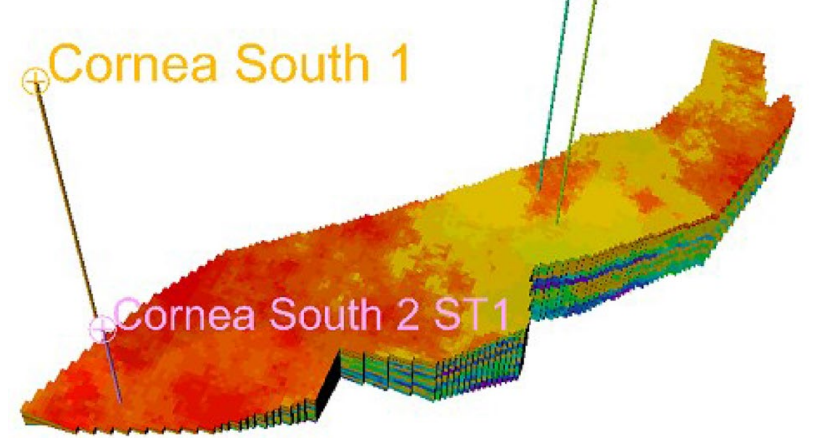

Fig. 5 Unfaulted Cornea Field

Table 2 Fluid model (Rashid et al. 2014b; Rotevatn and Fossen 2011; Saeid et al. 2018; Sern et al. 2012)

\begin{tabular}{ll}
\hline Initial condition & Value \\
\hline Datum depth & $-80 \mathrm{~m}$ \\
Datum pressure & $78 \mathrm{Bar}$ \\
Gas oil depth & $-771 \mathrm{~m}$ \\
Water contact depth & $-783.5 \mathrm{~m}$ \\
Minimum pressure & $64 \mathrm{Bar}$ \\
Maximum pressure & $83 \mathrm{Bar}$ \\
Reference pressure & $78 \mathrm{Bar}$ \\
Reservoir temperature & $51{ }^{\circ} \mathrm{C}$ \\
\hline
\end{tabular}

Figure 6 shows the Cornea Field with fault polygon displayed, while Fig. 7 shows the Cornea Field after the fault polygons were converted into faults. Table 5 shows the nature and position of the faults. In this case, the fault location is placed in between the well location.

Monzocchi algorithm gave higher fault permeability compared to Sperrevik algorithm, thus higher transmissibility values. Therefore, Monzocchi algorithm was used in this model. See Figs. 8 and 9 for the comparison of the fault 
Table 3 Porosity data (Rashid et al. 2014b; Rotevatn and Fossen 2011; Saeid et al. 2018; Sern et al. 2012)

\begin{tabular}{ll}
\hline Well name & Porosity \\
\hline Cornea 1 & 0.342 \\
Cornea 1B & 0.336 \\
Cornea South 1 & 0.346 \\
Cornea South 2ST1 & 0.346 \\
\hline
\end{tabular}

Table 4 Permeability data

\begin{tabular}{ll}
\hline Well name & Permeability \\
\hline Cornea 1 & N/A \\
Cornea 1B & N/A \\
Cornea South 1 & 183 \\
Cornea South 2ST1 & 44 \\
\hline
\end{tabular}

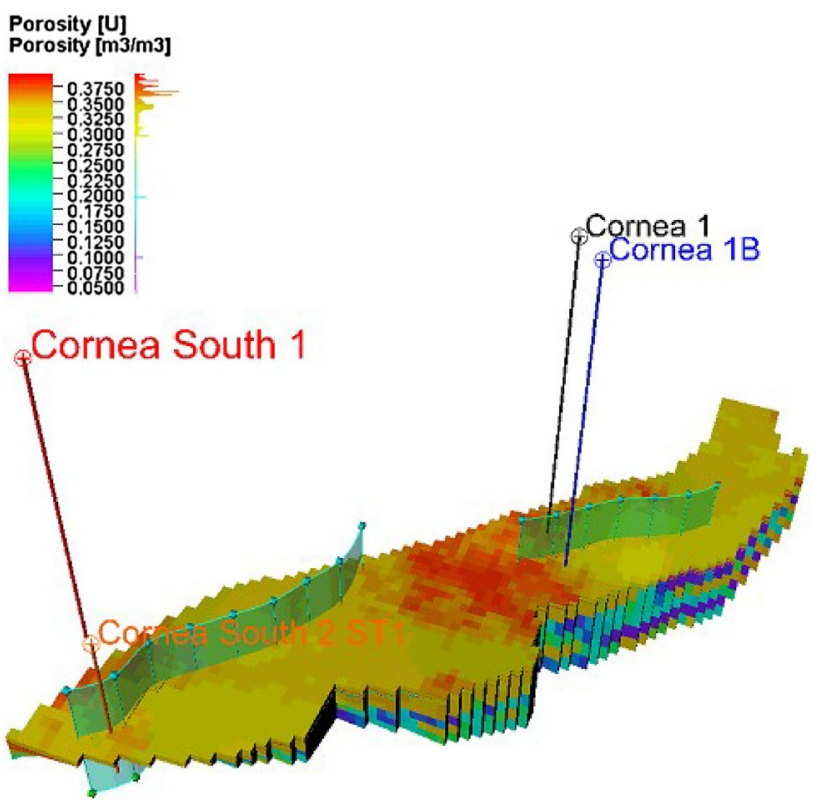

Fig. 6 Cornea Field with fault polygon displayed

transmissibility in $X$ and $Y$ direction by Monzocchi and Sperrrevik algorithm.

Figures $10,11,12,13$ and 14 show varying fault permeability effect from $0.5,1.0,1.5,10,100 \mathrm{mD}$ on fault transmissibility. From the trends, it shows that as the fault permeability increases, fault transmissibilities also increase. On the other hand, fault displacement-to-thickness ratio of 66 , 100,170 was also tested to determine the fault transmissibility. See Figs. 15, 16, 17 and 18. The fault transmissibilities also increase with increasing fault displacement thickness ratio value. Figure 14 (permeability $100 \mathrm{mD}$ ) shows

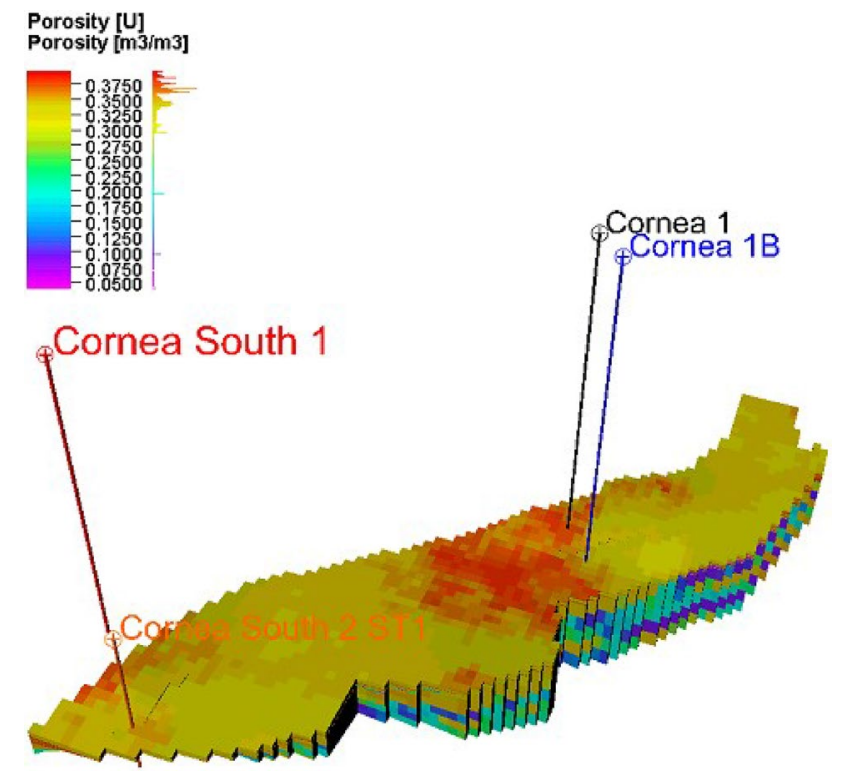

Fig. 7 Faulted model of Cornea Field

Table 5 Fault variables

\begin{tabular}{lll}
\hline Variable & Fault 1 & Fault 2 \\
\hline Nature & Normal faults & Normal faults \\
Location & Max: $-626.45 \mathrm{~m}$ & Max: $-630.24 \mathrm{~m}$ \\
& Min: $-931.41 \mathrm{~m}$ & Min: $-931.66 \mathrm{~m}$ \\
\hline
\end{tabular}

higher transmissibility compared with other permeabilities; therefore, these data were used to further determine the oil production using transmissibility multiplier. Transmissibility multiplier was varied from $0.2,0.5,1.0,1.5$ and 3.0 to determine its effects on transmissibility and oil production. See Figs. 18 and 19.

Figure 17 (fault displacement thickness ratio 170) also shows higher transmissibility; therefore, these data were used to further determine the oil production using transmissibility multiplier. Transmissibility multiplier was also varied from $0.2,0.5,1.0,1.5$ and 3.0 to determine its effects on transmissibility and oil production (Table 6). See Figs. 20 and 21. Figures 18, 19, 20 and 21 show that oil and water production increases with time. Thus, it shows that the higher the transmissibility multiplier, the more oil will be produced.

\section{Conclusions}

The report published by Tuohy (2009a) was basically based on the real appraisal and exploration on the Cornea Field. Shell conducted the appraisal drilling on the Cornea Central, 
Fig. 8 Transmissibility by Monzocchi algorithm

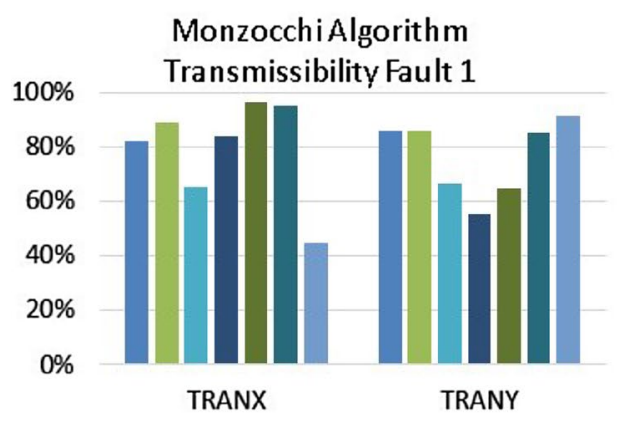

Fig. 9 Transmissibility by Sperrivik algorithm

Fig. 10 Permeability $0.5 \mathrm{mD}$ transmissibility trend

Fig. 11 Permeability $1.0 \mathrm{mD}$ transmissibility trend
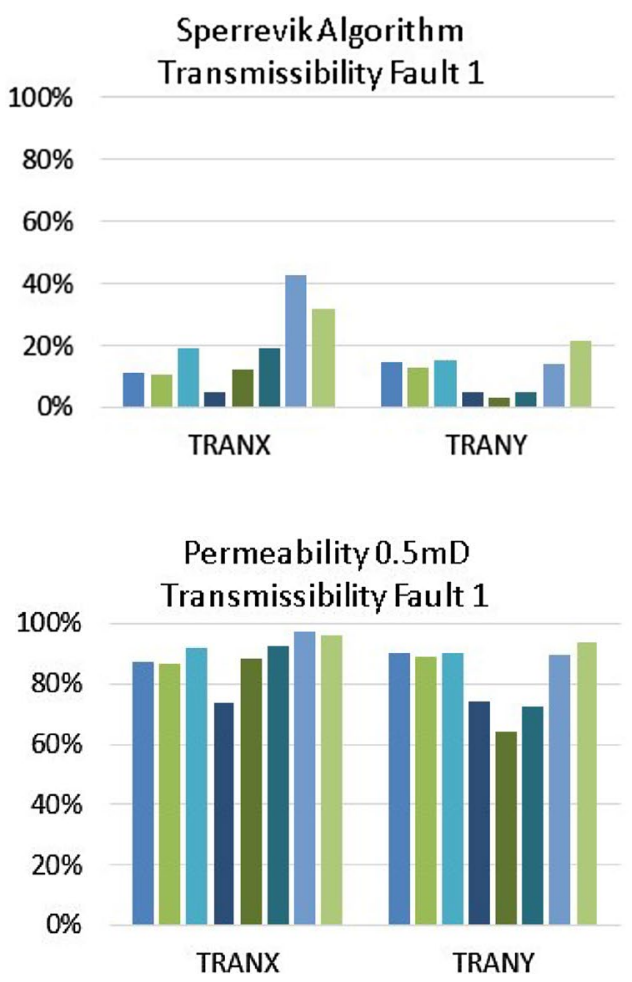

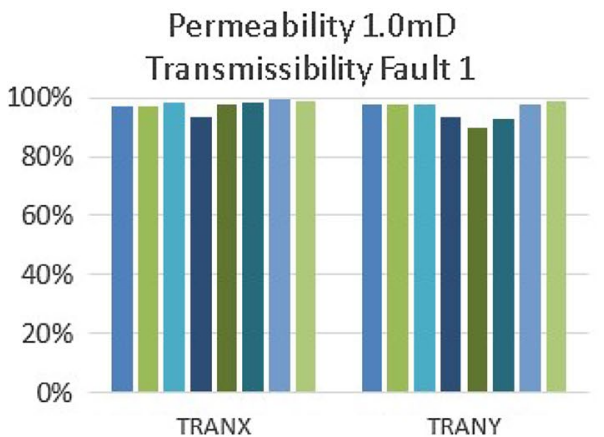

Cornea South and Cornea North. However, this research is based on simulating the reservoir to resemble the real reservoir and only focused on Cornea Central and Cornea North.

The exploration included nine wells drilled around the area. However, this research only focused on Cornea 1, Cornea 1B, Cornea South 1 and Cornea South 2 ST1. The
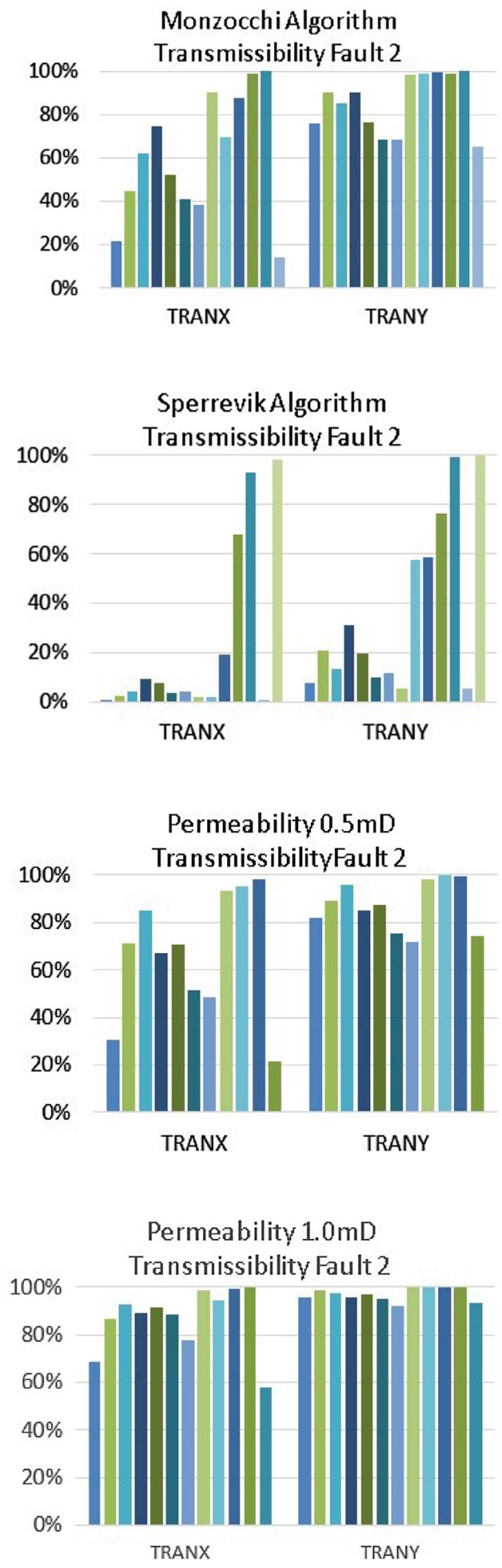

data from this well were reliable because it shows that wire logging and conventional core sample obtained by Shell from Cornea 2 ST2 and Cornea South 1 shows the best reservoir properties. The wells used in this research are the wells that have the evidence of producing the most from this potential oil-producing field. 
Fig. 12 Permeability $1.5 \mathrm{mD}$ transmissibility trend

Fig. 13 Permeability $10 \mathrm{mD}$ transmissibility trend

Fig. 14 Permeability $100 \mathrm{mD}$ transmissibility trend

Fig. 15 Displacement thickness ratio transmissibility trend
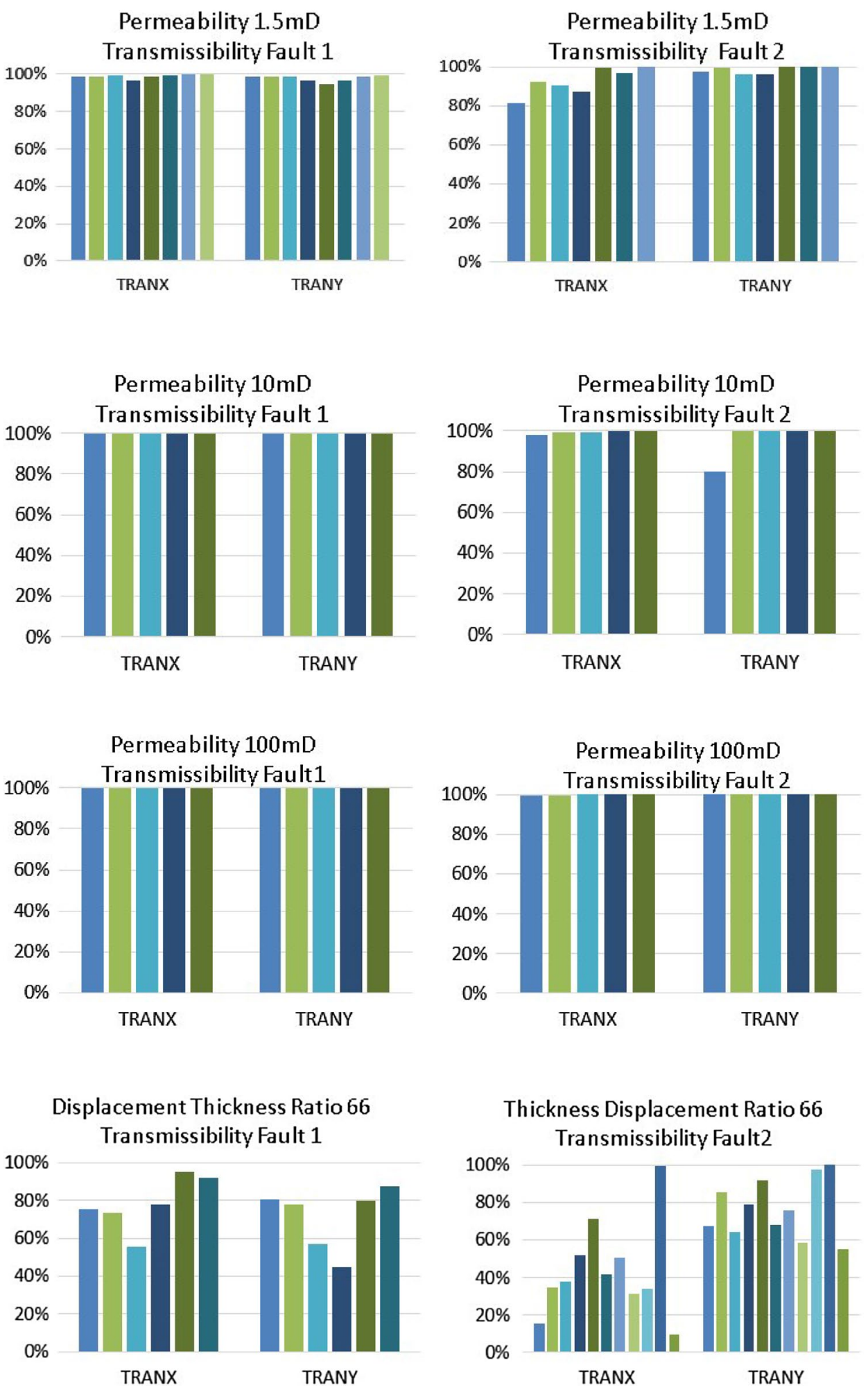

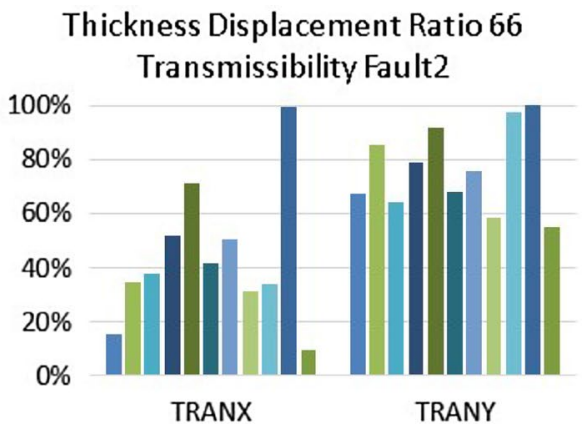

Therefore, the oil production obtained by different companies was used to compare the result obtained in this research.

This concludes few important findings:
1. Fault properties such as fault permeability and fault displacement thickness ratio are important to be considered in fault model transmissibility.

2. Fault permeability and fault displacement thickness ratio have a close relationship with transmissibility. It shows

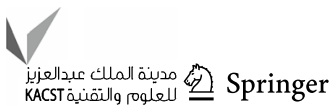


Fig. 16 Displacement thickness ratio transmissibility trend

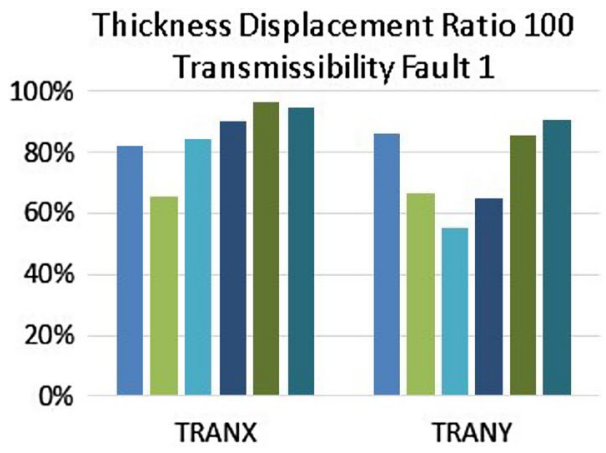

Fig. 17 Displacement thickness ratio transmissibility trend

\section{Thickness Displacement Ratio 170} Trasmissibility Fault 1

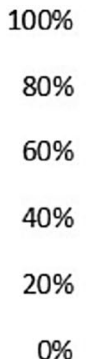

Thickness Displacement Ratio 100 Transmissibility Fault 2

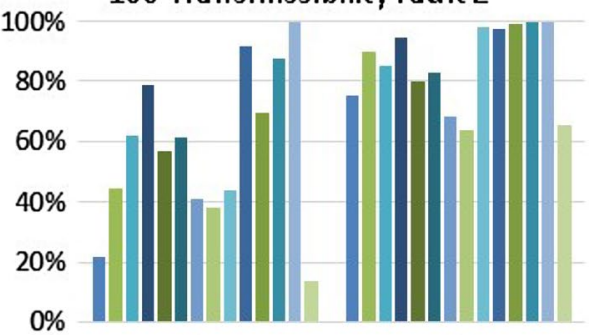

TRANX
Thickness Displacement Ratio 170 Transmissibility Fault 2

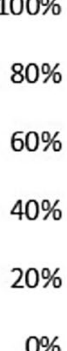

$0 \%$

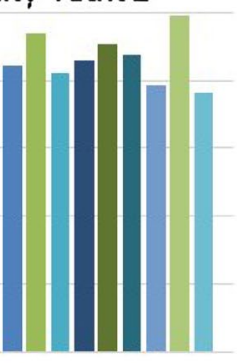

TRANY

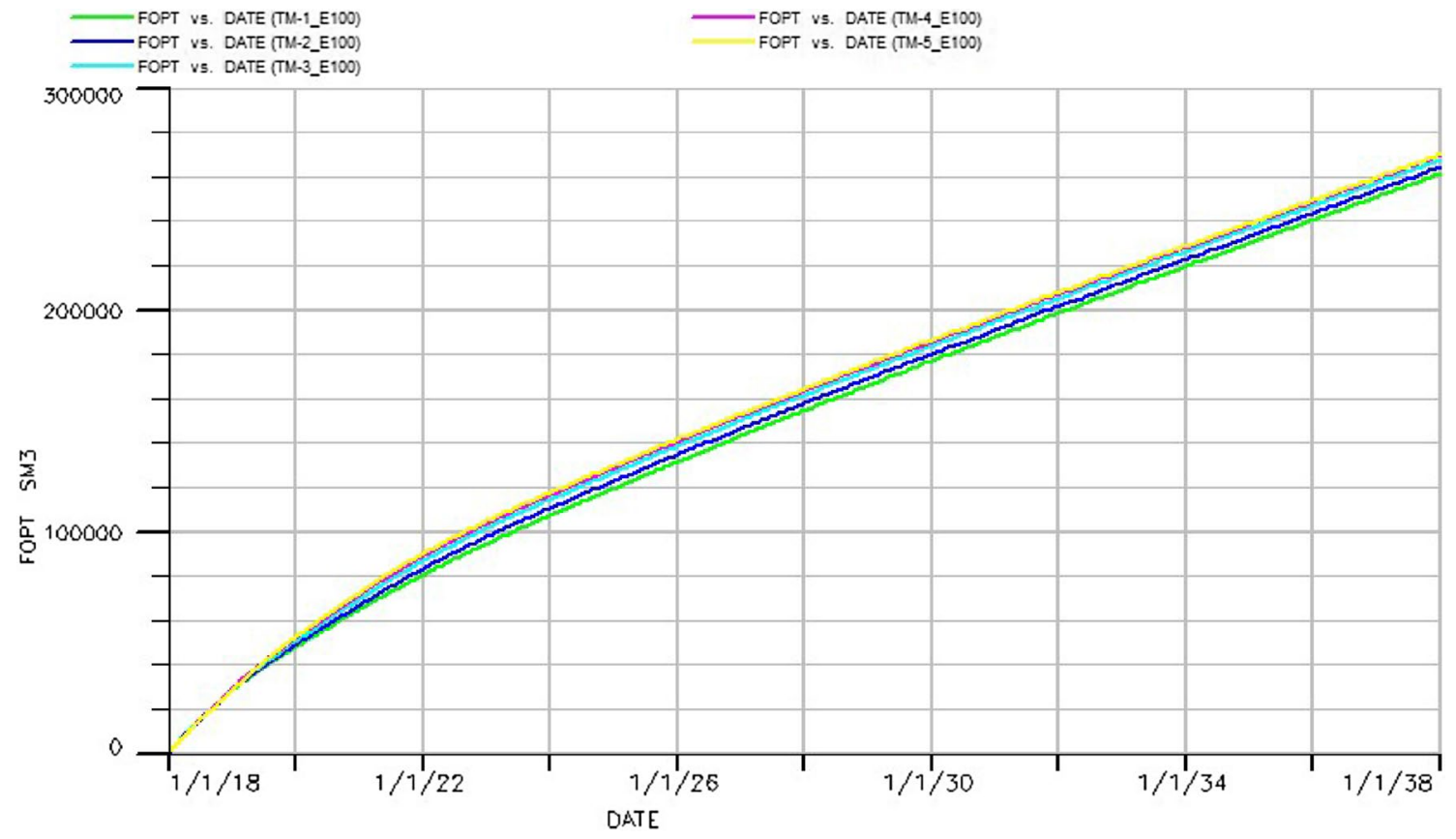

Fig. 18 Permeability $100 \mathrm{mD}$ : field oil production total for transmissibility multiplier of $0.2,0.5,1.0,1.5$ and 3.0

that the fault permeability and fault displacement thickness ratio increase proportionately with fault transmissibility.
3. Transmissibility multiplier was also important to be considered to see its effects on oil production. It shows that the transmissibility increases with the increase in transmissibility multiplier; thus, it increases oil production. 


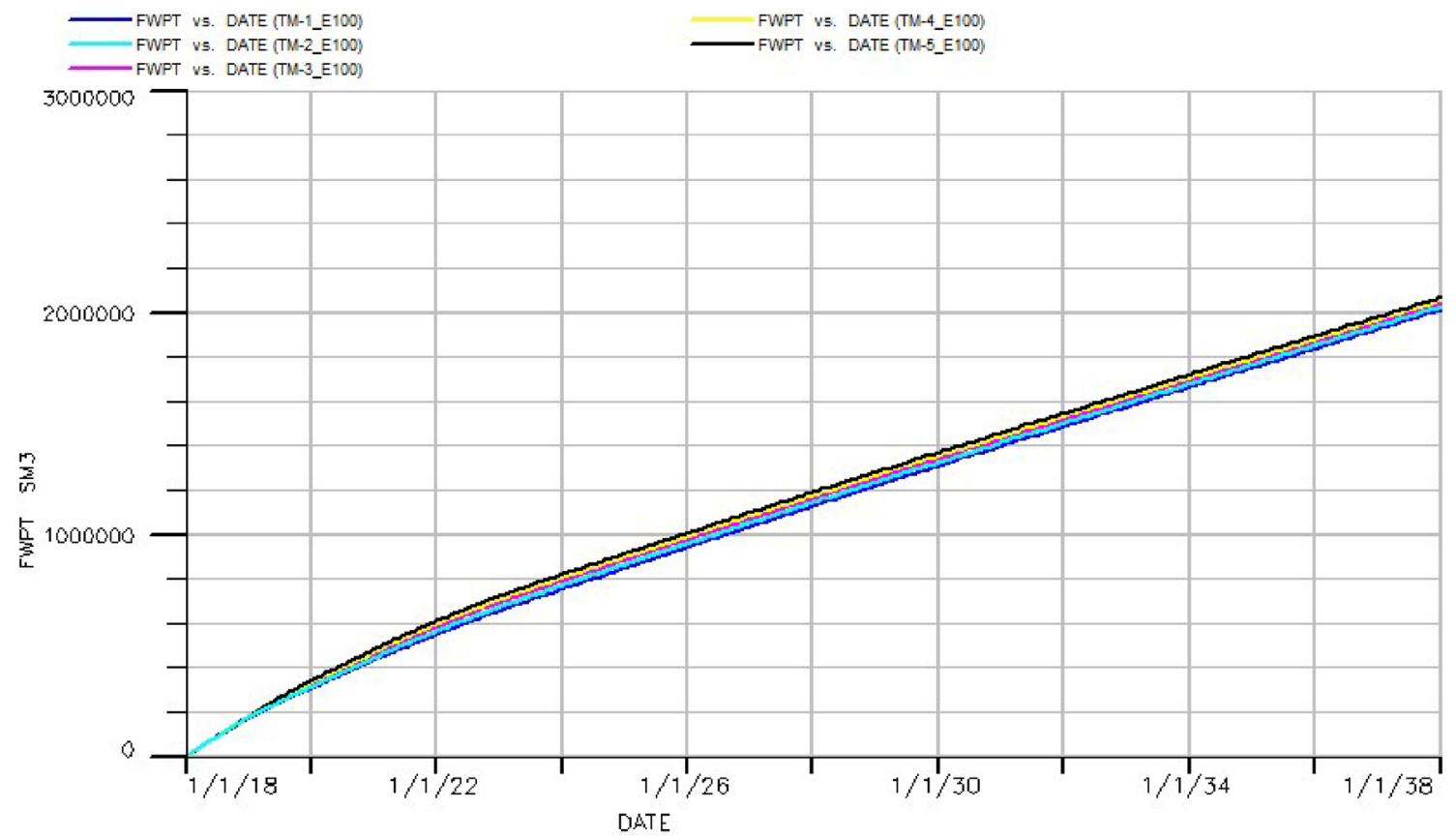

Fig. 19 Permeability $100 \mathrm{mD}$ : field water production total for transmissibility multiplier of $0.2,0.5,1.0,1.5$ and 3.0

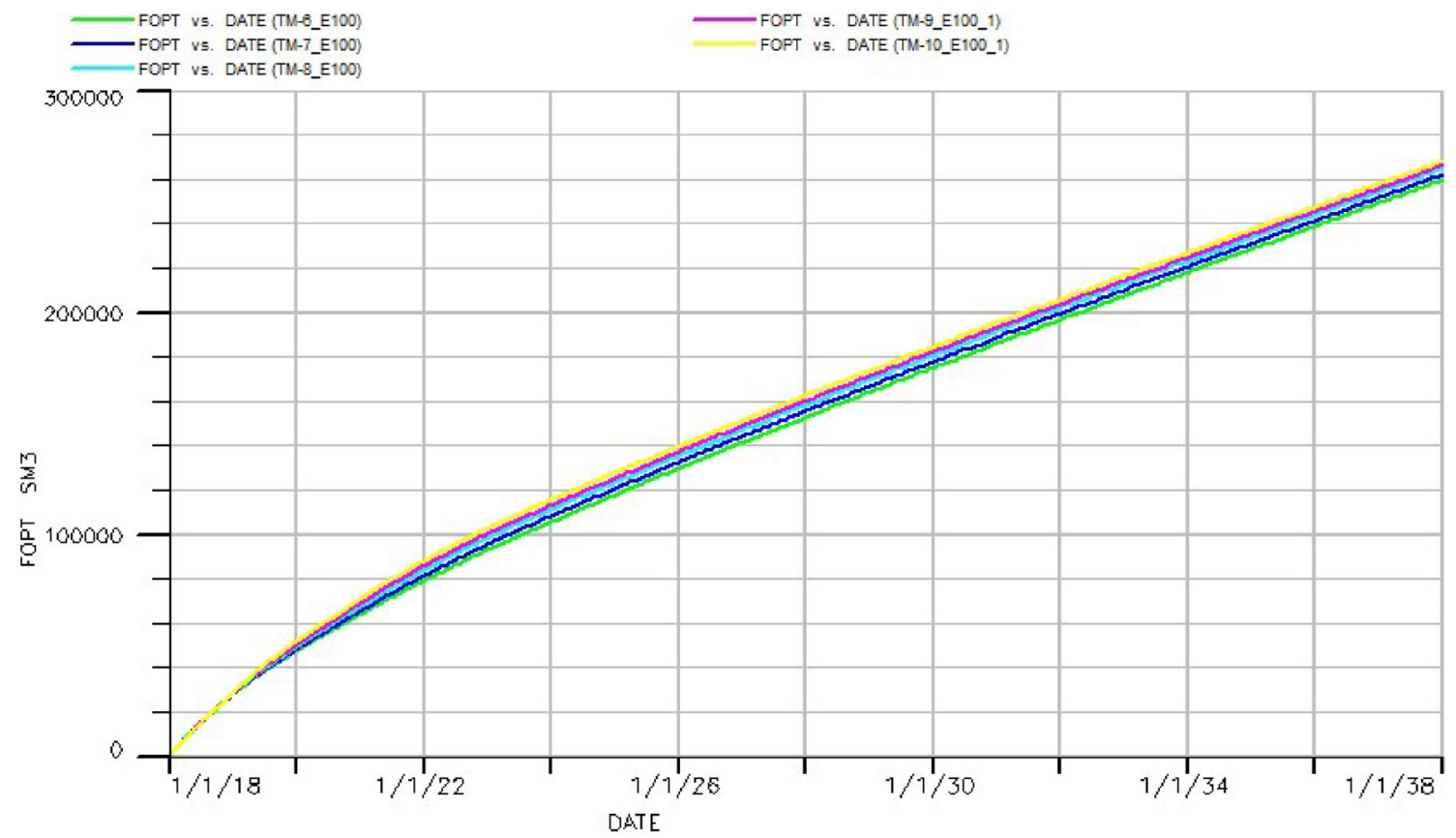

Fig. 20 Displacement/thickness 170: field oil production total for transmissibility multiplier of 0.2, 0.5, 1.0, 1.5 and 3.0

4. Fault analysis is important to be taken into account for successful exploration and production.

Hence, this paper contributes to the gap in the Cornea Field research related to fault structure existence. From the result, it is confirmed that the production has a direct relation to the reservoir structure and properties. Therefore, it is important to consider possible faults that exist in the reservoir during exploration and production. From the literature review, it showed that gas chimney was detected in the 


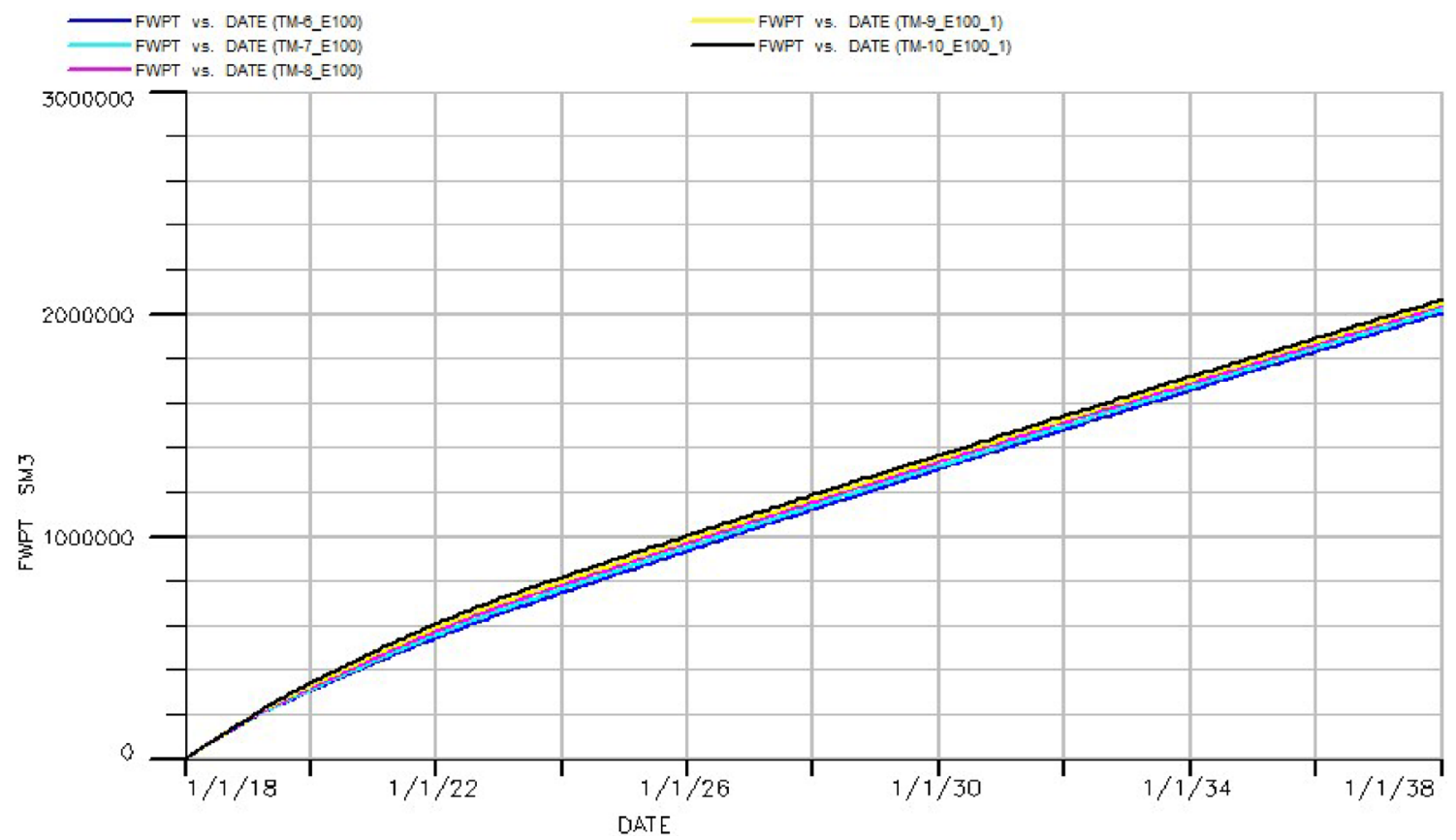

Fig. 21 Displacement/thickness 170: field water production total for transmissibility multiplier of 0.2, 0.5, 1.0, 1.5 and 3.0

Table 6 Results obtained for oil production

\begin{tabular}{lll}
\hline Fault property & TM & $\begin{array}{l}\text { Oil production } \\
\text { after 20 years } \\
\left(\mathrm{SM}^{3}\right)\end{array}$ \\
\hline Fault permeability $100 \mathrm{mD}$ & 3.0 & 270.00 \\
Fault displacement/thickness 170 & 3.0 & 268.20 \\
\hline
\end{tabular}

Cornea Field which can also have a significant impact on production. Therefore, future study can be considered on modeling the gas chimney in the Cornea Field for further understanding of the field framework. From the literature review, the Cornea Field was stated to have a gas chimney that exists within the reservoir. Therefore, more simulation illustration and research need to be done. This is to study the geological structure of the gas chimney and to see the impact of the gas chimney on the reservoir production.

Open Access This article is distributed under the terms of the Creative Commons Attribution 4.0 International License (http://creativeco mmons.org/licenses/by/4.0/), which permits unrestricted use, distribution, and reproduction in any medium, provided you give appropriate credit to the original author(s) and the source, provide a link to the Creative Commons license, and indicate if changes were made.

\section{Appendix 1}

\section{System Information}

Operating System: Windows 7 Professional 64-bit (6.1, Build 7601) Service Pack 1 (7601. win7sp1_ldr_escrow.190828-1732)

System Model: HP Z820 Workstation

BIOS: Default System BIOS

Processor: Intel(R) Xeon(R) CPU E5-2630 0 @ 2.30GHz (24 CPUs), 2.3GHz

Memory: $114688 \mathrm{MB}$ RAM

Available OS Memory: 114612MB RAM

DirectX Version: DirectX 11

Display Devices

Card name: NVIDIA Quadro K5000

Manufacturer: NVIDIA

Chip type: Quadro K5000

DAC type: Integrated RAMDAC

Device Key: Enum \PCI $\backslash$ VEN_10DE\&DEV_11BA\&

SUBSYS_0965103C\&REV_A1

Display Memory: $4095 \mathrm{MB}$

Dedicated Memory: $3072 \mathrm{MB}$

Shared Memory: $1023 \mathrm{MB}$

Current Mode: 1920 x 1200 (32 bit) (59Hz)

Monitor Name: Generic PnP Monitor 
Monitor Model: HP ZR2440w

Monitor Id: HWP2955

Native Mode: 1920 x 1200(p) $(59.950 \mathrm{~Hz})$

Output Type: DVI

Monitor Name: Generic PnP Monitor

Monitor Model: HP ZR2440w

Monitor Id: HWP2955

Native Mode: 1920 x 1200(p) $(59.950 \mathrm{~Hz})$

Output Type: DVI

Driver Name: nvd3dumx.dll,nvwgf2umx.dll,nvwgf2umx.

dll,nvd3dum,nvwgf2um,nvwgf2um

Driver File Version: 9.18.0013.3182 (English)

Disk \& DVD/CD-ROM Drives

Drive: C:

Free Space: $331.0 \mathrm{~GB}$

Total Space: $941.8 \mathrm{~GB}$

File System: NTFS

Model: LSI Logical Volume SCSI Disk Device Drive: D:

Free Space: $1.2 \mathrm{~GB}$

Total Space: $10.1 \mathrm{~GB}$

File System: NTFS

Model: LSI Logical Volume SCSI Disk Device

EVR Power Information

Current Setting: \{5C67A112-A4C9-483F-B4A71D473BECAFDC \} (Quality)

Quality Flags: 2576

\section{Appendix 2}

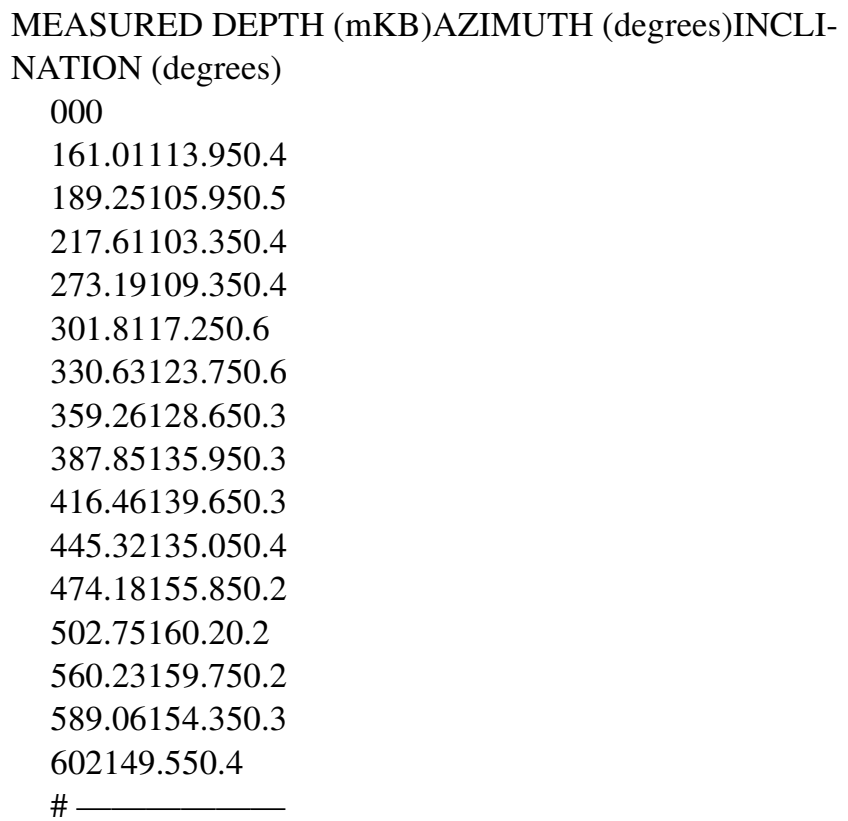

STRT.M 538.5816 :START DEPTH

STOP.M 845.0580 :STOP DEPTH

STEP.M 0.1524 :STEP

NULL. -999.25 :NULL VALUE

COMP. Shell :COMPANY

WELL. Cornea South 1 :WELL

FLD. Cornea :FIELD

LOC. :LOCATION

PROV. :PROVINCE

SRVC. :SERVICE COMPANY

CTRY. :COUNTRY

DATE. 211099 :LOG DATE

UWI. :UNIQUE WELL ID

LATI.DEG -1345'53.796"S : Latitude

LONG.DEG 124/27/36.698 : Longitude

GDAT. : Geodetic Datum

\#MNEM .UNIT API CODE Curve Description

DEPT .m : Along hole depth

CALI .IN : Caliper

GR .GAPI : Gamma Ray

KTH .GAPI : Gamma, Potassium + Thorium

K .\% : Potassium Concentration

M2R1 .OHMM : 2 foot vertical resolution matched res.

- DOI 10 inch

M2R2 .OHMM : 2 foot vertical resolution matched res.

- DOI 20 inch

M2R3 .OHMM : 2 foot vertical resolution matched res.

- DOI 30 inch

M2R6 .OHMM : 2 foot vertical resolution matched res.

- DOI 60 inch

M2R9 .OHMM : 2 foot vertical resolution matched res.

- DOI 90 inch

M2RX .OHMM : 2 foot vertical resolution matched res.

- DOI 120 inch

DT .US/F : Sonic

TH .PPM : Thorium Concentration

U .PPM : Uranium Concentration

WTBH .DEGC : Well Temperature

GR1 .GAPI : Gamma Ray

WTBH .DEGC : Well Temperature

CNCF .PU : Field Normalized Borehole Corrected Compensated Neutron Porosity

PE .B/E : Photoelectric Factor

ZCOR .G/C3 : Bulk Density Correction

ZDEN .G/C3 : Compensated Bulk Density

MBVI .PU : Bulk Volume Irreducible

MBVM .PU : Bulk Volume Moveable

MCBW .PU : Clay Bound Porosity

MPHE .PU : MRIL Effective Porosity

MPHS .PU : Total Porosity

MPRM .MD : Permeability

DTC .US/F : Delta-T, Compressional

DTS .US/F : Delta-T, Shear 
DAZ .DEG : Dip Azimuth

DEV .DEG : Deviation

GR2 .GAPI : Gamma Ray

\# HOLE AND CASING DATA:

\# $\quad \mathrm{Hole} \quad \mathrm{H}$ o l e C a s i g C a s i ng

WeightGradeJointsCementTOC

\# SizeDepthSizeDepthlb/ft

\# 36"145m30"141m310X-52519 sx G at SG 1.9

\# 12.25"616m9 5/8"612m47L-80370 sx G at SG

1.5Seafloor

\# 204 sx G at SG 1.9

\# 8.5" $847 \mathrm{~m}$

\# \#

\# TEMPERATURES:

\# Depth DrillerLoggerTempLog TypeTime since circCirc

Time

\# 837m50.5 deg CHDIL-MAC-GR-CAL5.75 hrs1.25
\# 52.8 deg CZDEN-DSL-MRIL11.5 hrs
\# 58.7 deg CFMT-GR
\# \#
\# MUD PROPERTIES:
\# Depth (L)Fluid TypeSGVis.pHFl ccRmRmfRmc
\# 847mSOBM1.1087na3.0na
\# Oil:water63:37Whole mud Chlorides:53000 mg/l

\section{References}

A TNO-CSIRO-ISES Joint Industry Project (2009) Dynamic fault seal behaviour in petroleum reservoirs. https://www.energydelta.org/ uploads/fckconnector/4bc5dfaf-e298-45b6-bfbb-f8104531895c

Ahmed W (2013) Flow modelling across faults. In: SPE YP technical showcase event.https://higherlogicdownload.s3.amazonaws. com/SPE/a77592d6-ec9a-43b1-b57bc7275fb91cb0/UploadedIm ages/SPE\%20Past\%20Event\%20Presentation\%20Downloads/28_ MAY_2013\%20Wahab\%20Ahmed\%20-\%20FlowModellingAcros sFault.pdf

Alkaif MAO (2015) Integration of depositional process modelling, rock physics and seismic forward modelling to constrain depositional parameters. In: Department of Exploration Geophysics. http://hdl. handle.net/20.500.11937/110

Australia G (2012a) Petroleum geological summary release area W123, W12-4 and W12-5 Caswell Sub-Basin, Browse Basin, Western Australia

Australia G (2012b) Release areas W12-3, W12-4 And W12-5 Caswell Sub-Basin

Australia G, Geoscience Australia (1998a) Well completion report cornea south 1. http://dbforms.ga.gov.au/www/npm.well. results?pTimescale $=$ A $\&$ pMapLayer $=\&$ Confid $=$ Y \&pTitl $\mathrm{e}=$ AR $11 \% 20$ Caswell\%20Sub-basin

Australia G, Geoscience Australia (1998b) Well completion report cornea south 2 ST2. http://dbforms.ga.gov.au/www/npm.well. results?pTimescale $=$ A $\&$ pMapLayer $=\&$ ponfid $=$ Y \&pTitl $\mathrm{e}=\mathrm{AR} 11 \% 20$ Caswell\%20Sub-basin

Australia G, Australia Geoscience (2011a) Petroleum geological summary, release area W11-1 Caswell Sub-basin. Browse Basin, Western Australia
Australia G, Australia Geoscience (2011b) Release area W11-1 Caswell Sub-Basin, Browse Basin, Western Australia. http://dbfor ms.ga.gov.au/www/npm.well.results?pTimescale=A\&pMapL ayer $=\&$ ponfid $=$ Y\&pTitle $=$ AR 11\%20Caswell\%20Sub-basin

Bishop MG (1999) A total petroleum system of the Browse Basin. Late Jurassic, Early Cretaceous-Mesozoic, Australia. https://doi. org/10.3133/ofr9950I, https://pubs.er.usgs.gov/publication/ofr99 $50 \mathrm{I}$

Byberg A (2009) Importance of fault communication for predicted Snorre performance. https://uis.brage.unit.no/uis-xmlui/handl e/11250/183255

Cerveny K, Davies R, Dudley G, Fox R, Kaufman P, Knipe R, Krantz B (2005) Reducing uncertainty with fault-seal analysis. Oilfield Rev 16(4):38-51

Costa BG, Teresa RM, Costa SA (2016) Production strategy optimization of an oilfield

Fisher Q, Jolley SJ (2007) Treatment of faults in production simulation models. In: Jolley SJ, Barr D, Walsh JJ, Knipe RJ (eds) Structurally complex reservoirs, vol 292. Geological Society, London, pp 219-233. https://doi.org/10.1144/SP292.13 (Special Publications)

Flodin E, Durlofsky L, Yeten B (2001) Representation of fault zone permeability in reservoir flow models. In: SPE annual technical conference and exhibition. Society of Petroleum Engineers, New Orleans, Louisiana. https://doi.org/10.2118/71617-MS

Frischbutter AA, Fisher QJ, Namazova G, Dufour S (2017) The value of fault analysis for field development planning. Pet Geosci 23(1):120-133

Geoscience Australia (1997) Well completion report cornea 1. http://dbforms.ga.gov.au/www/npm.well.results\%3FpTimesca le $=$ A $\&$ pMapLayer $=\&$ pConfid $=$ Y \&pTitle $=$ AR $11 \% 20 \mathrm{Cas}$ well\%20Sub-basin

Houwers ME, Heijnen LJ, Becker A, Rijkers R (2015) A workflow for the estimation of fault zone permeability for geothermal production a general model applied on the Roer Valley Graben in the Netherlands. In: Proceedings world geothermal congress, pp 19-25

Ingram GM, Eaton S, Regtien JMM (2000) Cornea case study: lesson for the future. APPEA J 40(1):56-65

Ishak MA, Islam MA, Shalaby MR, Hasan N (2018) The application of seismic attributes and wheeler transformations for the geomorphological interpretation of stratigraphic surfaces: a case study of the F3 block, Dutch offshore sector, north sea. Geosciences 8:79. https://doi.org/10.3390/geosciences8030079

Khan MNH, Fletcher C, Evans G, He Q (2001) CFD modeling of free surface and entrainment of buoyant particles from free surface for submerged jet systems, vol 369. American Society of Mechanical Engineers, Heat Transfer Division, HTD, pp $115-120$

Khan MNH, Fletcher C, Evans G, He Q (2003) CFD analysis of the mixing zone for a submerged jet system. In: Proceedings of the ASME fluids engineering division summer meeting, vol 1 , pp 29-34

Khan MNH, Witt P, Brooks G, Barton T, Nagle M (2006) Design of supersonic nozzles for ultra-rapid quenching of metallic vapours. In: TMS Annual Meeting, pp 699-709

Khan A, Abdullah AB, Hasan N (2012) Event based data gathering in wireless sensor networks. In: Wireless sensor networks and energy efficiency:protocols, routing and management, pp 445-462. https://doi.org/10.4018/978-1-4666-0101-7.ch021

Kimura S, Kaneko H, Ito T, Minagawa H (2015) Investigation of fault permeability in sands with different mineral compositions (Evaluation of Gas Hydrate Reservoir). Energies 8(7):72027223. https://doi.org/10.3390/en8077202 
Gas MO (2010) Quarterly activity report-ASX. https://www. firstau.com/wpcontent/uploads/2018/09/180830_PUB001_ IGR_2018_03_22_final.pdf

Ltd CRP (2014) Grant of retention lease WA-54-R greater cornea fields. https://www.worldoil.com/news/2014/6/13/grant-of-reten tion-lease-wa-54-r-greater-cornea-fields. Accessed 23 Sept 2019

Manzocchi T, Walsh JJ, Nell P, Yielding G (1999) Fault transmissibility multipliers for flow simulation models. Pet Geosci 5:53-63. https://doi.org/10.1144/petgeo.5.1.53

Manzocchi T, Heath AE, Palananthakumar B, Childs C, Walsh JJ (2008) A study of the structural controls on oil recovery from shallow-marine reservoirs. Pet Geosci 14(1):55-70. https://doi. org/10.1144/1354-079307-786

Manzocchi T, Childs C, Walsh JJ (2010) Faults and fault properties in hydrocarbon flow models. Geofluids 10:94-113

Michele GB (1999) A total petroleum system of the browse Basin. Australia: Late Jurassic, Early Cretaceous-Mesozoic

Naser J, Alam F, Khan M (2007) Evaluation of a proposed dust ventilation/collection system in an underground mine crushing plant. In: Proceedings of the 16th Australasian fluid mechanics conference, 16AFMC, pp 1411-1414

Obriena GW, Lawrence GW, Williams GM, Glenn AK, Barrett K, Lech AG, Edwards M, Cowley DS, Boreham R, Summons CJ, Roger E, Shelf Y (2005) Yampi Shelf, Browse Basin, NorthWest Shelf, Australia: a test-bed for constraining hydrocarbon migration and seepage rates using combinations of $2 \mathrm{D}$ and $3 \mathrm{D}$ seismic data and multiple, independent remote sensing technologies. Mar Pet Geol 22(4):517-549. https://doi.org/10.1016/j. marpetgeo.2004.10.027

Paul P, Zoback M, Hennings P (2007) Fluid flow in a fractured reservoir using a geomechanically-constrained fault zone damage model for reservoir simulation. In: SPE annual technical conference and exhibition. Society of Petroleum Engineers, Anaheim, California, USA. https://doi.org/10.2118/110542-MS

Poidevin SL, Kuske T, Edwards D, Temple R (2015) Australian petroleum accumulations report 7 browse basin: Western Australia and territory of Ashmore and Cartier Islands adjacent area, 2nd edn, Record 2015/10. Geoscience Australia, Canberra. https://doi.org/10.11636/Record.2015.010

Rashid H, Hasan N, Nor MIM (2014a) Accurate modeling of evaporation and enthalpy of vapor phase in $\mathrm{CO}_{2}$ absorption by amine based solution. Sep Sci Technol (Phila) 49:1326-1334. https:// doi.org/10.1080/01496395.2014.882358

Rashid H, Hasan N, Nor MIM (2014b) Temperature peak analysis and its effect on absorption column for $\mathrm{CO}_{2}$ capture process at different operating conditions. Chem Prod Process Model 9:105-115. https://doi.org/10.1515/cppm-2013-0044

Rotevatn A, Fossen H (2011) Simulating the effect of subseismic fault tails and process zones in a siliciclastic reservoir analogue: implications for aquifer support and trap definition. Mar Pet Geol 28(9):1668-1662
Saeid NH, Hasan N, Ali MHBHM (2018) Effect of the metallic foam heat sink shape on the mixed convection jet impingement cooling of a horizontal surface. J Porous Media 21:295-309. https://doi. org/10.1615/JPorMedia.v21.i4.10

Sern WK, Takriff MS, Kamarudin SK, Talib MZM, Hasan N (2012) Numerical simulation of fluid flow behaviour on scale up of oscillatory baffled column. J Eng Sci Technol 7:119-130

Sorkhabi R, Tsuji Y (2005) The place of faults in petroleum traps. AAPG Mem 85:1-31

Taylor DS (2016) Geographic information systems online training modules, chapter 4. https://people.wou.edu/ taylors/g492/g492w 07.htm

Toft RE, Paulus SL, Salamanca M, Helle S, Zhou J, Rasta M (2012) Simulation of the EOR method "In-depth profile control "by transissibility modification in Eclipse. http://www.ipt.ntnu.no/ klepp e/pub/Gullfaks-Reports-2012/Technical/G1_Technical_Repor t.pdf

Tuohy JG (2009a) Acquisition of an $8 \%$ interest in WA-342-P (Cornea). https://www.nsx.com.au/ftp/news/021722139.PDF. Accessed 22 Sept 2019

Tuohy JG (2009b) Independent geologist's report. https://www. firstau.com/wpcontent/uploads/2018/09/180830_PUB001_ IGR_2018_03_22_final.pdf

Wennberg OP, Logstein JI, Hashemi N (2012) Fluid flow effects of faults in carbonate reservoirs, an example from the Kharyaga field. In: 3rd EAGE International Conference on Fault and Top Seals. Research Gate, Russia

Wenning QC, Madonna C, Haller AD, Burg JP (2018) Permeability and seismic velocity anisotropy across a ductile-brittle fault zone in crystalline rock. Solid Earth 9:683-697

Witt P, Khan MNH, Brooks G (2007) CFD modelling of heat transfer in supersonic nozzles for magnesium production. In: TMS Annual Meeting, pp 123-132

Zene MTAM, Hasan N, Ruizhong J, Zhenliang G, Trang C (2019) Geological modeling and upscaling of the Ronier 4 block in Bongor basin, Chad. J Pet Explor Prod Technol. https://doi.org/10.1007/ s13202-019-0712-z

Zhalehrajabi E, Rahmanian N, Hasan N (2014) Effects of mesh grid and turbulence models on heat transfer coefficient in a convergent-divergent nozzle. Asia Pac J Chem Eng 9:265-271. https:// doi.org/10.1002/apj.1767

Zijlstra EB, Reemst PHM, Fisher QJ (2016) Incorporation of fault properties into production simulation models of Permian reservoirs from the southern North Sea. Geol Soc 292:295-308

Publisher's Note Springer Nature remains neutral with regard to jurisdictional claims in published maps and institutional affiliations. 